\title{
Hamster Chondrosarcoma
}

National Cancer Institute

\section{Source}

National Cancer Institute. Hamster Chondrosarcoma. NCI Thesaurus. Code C134957.

A chondrosarcoma that occurs in a hamster. 